\title{
Ideas and Practice of Medical Discipline Laboratory Construction under the Healthy China Strategy
}

\author{
Xiulan Yang, Xiaoguang Chen, Lian Liu, Jiangrong Huang, Limin Zhang \\ Experimental Teaching Center, Medical School of Yangtze University, Jingzhou, China \\ Email: 406490115@qq.com
}

How to cite this paper: Yang, X. L., Chen, X. G., Liu, L., Huang, J. R., \& Zhang, L. M. (2021). Ideas and Practice of Medical Discipline Laboratory Construction under the Healthy China Strategy. Open Journal of Social Sciences, 9, 243-248.

https://doi.org/10.4236/jss.2021.91017

Received: December 22, 2020

Accepted: January 17, 2021

Published: January 20, 2021

Copyright $\odot 2021$ by author(s) and Scientific Research Publishing Inc. This work is licensed under the Creative Commons Attribution International License (CC BY 4.0).

http://creativecommons.org/licenses/by/4.0/

\begin{abstract}
University laboratory is an important place for experimental teaching, scientific research and social service, as well as an important platform for cultivating students' practical ability and innovation ability. This paper takes the Yangtze university which is a comprehensive local university as an example, introduces the present situation and problems of laboratory construction and practical teaching of medical disciplines. And it combines with the specific requirements of speeding up the construction of "double first-class" undergraduate education in our university, discussing the health medical laboratory construction under China's strategic ideas and specific measures, from strengthening the construction of laboratory information, improving the system of laboratory management, the reasonable allocation of resources, increasing the experimental technical team construction of several aspects.
\end{abstract}

\section{Keywords}

Healthy China, Laboratory Construction, Experimental Technical Team

\section{Introduction}

In the report to the $19^{\text {th }}$ National Congress of the Communist Party of China, the CPC Central Committee elevated the "healthy China Building" to a national strategic position of priority for development. The implementation of the healthy China strategy requires not only perfecting the health policy but also deepening the reform of the system, strengthening the construction of medical personnel, and ensuring the supply of medical professionals in various disciplines, so as to ensure the healthy and orderly development of China's medical and health undertakings. Based on the new era of health in China construction of the medical 
education put forward new requirements and current medical discipline problems of laboratory construction and management, this research through to the students from all departments of medical, similar colleges and universities set up medical education and health care institutions on the basis of extensive research, according to the requirements of the state ministries file spirit, combining the reality of our university of local comprehensive university, actively explore to meet the needs of times and social development needs of laboratory reform measures, in order to comprehensively improve the level of medical laboratory construction, comprehensively enhance the connotation of medical laboratory construction and the quality of teaching, to train first-class medical personnel and serve the construction of a healthy China.

\section{Problems Existing in Laboratory Construction and Practical Teaching of Medical Discipline}

\subsection{Laboratory Information Construction and Application Is Insufficient, and Big Data Mining Is Not Deep}

In schools and the strong support and leadership of the state-owned assets management, we have established provincial experimental teaching demonstration center of medical laboratory and medical virtual simulation experiment teaching platform, but teaching experimental center of information management system in a more experiment data save, task, teaching plans of basic system application level, the experiment course arrangement, experimental equipment utilization information such as statistics, are mostly manual operation, the departments in a timely manner. To effectively understand the current situation of the laboratory and influence scientific decision-making. The timeliness of data information sharing is not high. Different experiments generate different information at any time, including the data information of experimental equipment and experimental consumables demand, and the information obtained and to be analyzed during the experiment, etc., which cannot be updated and shared in a timely and effective manner (Ji, 2014). The deep level management function, decisionmaking service support and management data mining of teaching informationization have not been implemented personalized and knowledge-based, there are few management systems suitable for business, the imitative system with a single function cannot really play the role due to the laboratory, and many modules of the management system are useless.

\subsection{The Laboratory Management Mode and Operation Mechanism Fail to Keep Pace with the Times}

Although the medical laboratory has established the responsibility management system, the management mode is relatively backward, the laboratory openness and sharing is not enough, and the laboratory rules and regulations need to be further improved. Most of the laboratories are still divided according to majors or courses, and each laboratory is independent and integrated, which restricts 
the mutual penetration between disciplines. It is not possible to carry out crossdisciplinary comprehensive experiments, especially interdisciplinary innovation experiments, which, to a large extent, restricts the cultivation of students' innovation quality and ability (Zhu, 2018; Yang \&Wu, 2018).

\subsection{Insufficient Investment in Laboratory Construction Funds and Lack of Reasonable Allocation of Experimental Resources}

As a comprehensive university, medical discipline laboratory construction funds are limited, laboratory infrastructure construction is poor. Due to the great breakthrough of discipline construction in the construction of new specialized laboratories, limited resources also limit the development of existing laboratories: some teaching instruments and equipment are aging, and the insufficient number of experimental instruments and equipment still exists, which cannot fully meet the needs of practical teaching in the school. The area of teaching laboratory per student is limited, and there are common or multi-purpose laboratories. The laboratory setting is relatively scattered, with the phenomenon of repeated construction, "small but complete", less shared resources, repeated acquisition of instruments and equipment, and serious waste of resources.

\subsection{Insufficient Attention Is Paid to the Construction of Experimental Technical Team}

Traditional education emphasizes theory over practice, believing that experimental teaching is a supplement to theoretical teaching. Experimental teachers are also regarded as auxiliary teaching personnel with low status, insufficient attention and great difficulty in promotion of professional titles. Titles and education structure is unreasonable, high-quality talent stay, staffing shortfall, researchers added is not in place in time (Dong \& Ao, 2019), a vicious cycle lead to cannot give full play to its technical personnel in the laboratory construction and management of the enthusiasm, initiative and creativity (Dong \& Ao, 2019), also has restricted the laboratory construction and development.

\section{Ideas and Practice of Medical Discipline Laboratory Construction under the Healthy China Strategy}

\subsection{Strengthen the Laboratory Information Construction}

Under the background of emphasizing informatization and big data, according to the laboratory status quo of comprehensive university and the construction plan of double first-class undergraduate, relying on the Internet of things, "Internet +", intelligent sensing and control and other information technology means, "private customization" is in line with the actual laboratory intelligent integrated operation management system of our university. It not only provides conditions for remote guidance of experimental scheme and equipment operation, laboratory appointment, experimental safety, management of experimental consumables and personnel, experimental process record, etc., but also promotes the safety and 
standardized management of laboratories at all levels and of all kinds, providing security guarantee for the open sharing of experimental resources.

\subsection{Improving the Laboratory Management System}

Scientific and reasonable operation and management mechanism can guarantee the laboratory to serve the teaching and scientific research better. Based on the actual situation of our medical laboratory, we have constantly improved and strengthened the laboratory management system and system construction, and successively introduced regulations and rules for the management of experimental technicians, experimental instruments and equipment, open sharing of instruments and equipment, and laboratory safety and environmental protection. In addition, according to the problems of laboratory construction, we discuss and formulate feasible laboratory construction and planning for the next academic year every semester, so as to better carry out laboratory construction.

\subsection{Increase Laboratory Investment and Optimize Resource Allocation}

Due to the limited capital investment in the laboratory by comprehensive colleges and universities, we used many ways and channels to raise funds. For example, school-enterprise cooperation, alumni donation and so on. In order to make the limited funds to play a bigger benefit, we implement the project management, laboratory construction priorities, concentrated into, before purchasing instruments and equipment, We invite experts to carry out feasibility study, examination and approval, acceptance inspection, the whole process of supervision, inspection and management, so as to ensure that the construction project is the most urgently needed project at present, which is most closely integrated with experimental teaching reform, laboratory evaluation and professional certification.

For closely related disciplines, the way of joint construction and open sharing should be adopted to integrate laboratories and establish laboratories with relatively concentrated functions, under the unified management of specially-assigned personnel. This not only expands the scale of the laboratory, but also reduces the repeated configuration of experimental instruments and equipment, improves the utilization rate of equipment, saves funds, optimizes the allocation of laboratory resources, and makes it more convenient for the overall coordination and unified management of instruments, equipment and personnel.

\subsection{Improving the Construction of Experimental Technical Team}

Experimental teaching and theoretical teaching are two inseparable parts of college teaching (Diao, 2015). Experimental teaching is an effective way for medical students to deeply understand and consolidate theoretical knowledge and an important means to improve the comprehensive quality of medical students. As the "housekeeper" of the laboratory, experimental technical teams play an im- 
portant role in the process of laboratory construction and operation management. Therefore, experimental teachers should be equivalent to teachers in concept and establish incentive policies suitable for experimental technical personnel in terms of performance allocation, title promotion, business training, etc. (Zheng, et al., 2019). Only by finding a sense of identity in concept and remuneration we can attract more experimental teachers to devote more enthusiasm to their work and work better (Tang, Wang, \& Guo, 2020).

Based on the new requirements of health China construction in the new era for medical education, the new challenges for experimental technicians are presented. We should make a feasible study plan on the problems we are facing, and pay attention to in-service learning, professional training and academic exchange of experimental technicians. For new teachers, through the tutorial system, one-to-one guidance and support, so that they can quickly enter the role. Regularly invite experts and scholars in related fields to give lectures. Go to other universities for research, study, academic exchange, etc. Through different channels and different forms of learning, the comprehensive quality and level of experimental technicians are improved (Gu, Xu, \& Guo, 2018).

Experimental technicians are more enthusiastic in their work. They can take advantage of the favorable working conditions in the laboratory to take the initiative to bring personal problems encountered in scientific research for exploration, and introduce scientific research into experimental teaching to explore new experimental teaching methods constantly, so as to promote the improvement of experimental teaching quality. The platform of scientific research center of our college also brings opportunities to the development of teachers and experimental technical team. In order to strengthen the training of experimental technical personnel in scientific research thinking and practical ability, the college also encourages experimental personnel to participate in scientific research and innovation, write scientific research and teaching papers, and give appropriate rewards to motivate teachers. In recent years, many experimental technicians have applied for the projects of municipal Bureau of Science and Technology and provincial Commission of Health and Family Planning and obtained the approval. Every year, some experimental technicians actively summarize the practical teaching experience and publish teaching and research papers.

\section{Conclusion}

Medical laboratory plays an important role in higher education. Laboratory construction and management in colleges and universities are related to the educational quality, scientific research level and school-running benefits of a school (Diao, 2015). Medical laboratory construction and management is a systematic project, which is related to all aspects. As a comprehensive university, although we have made some achievements, we are still groping forward. We must constantly learn the advanced experimental teaching concepts of other universities, strengthen the laboratory information construction, improve the rules and reg- 
ulations of the laboratory, reasonably allocate the resources to achieve the optimization, and constantly strengthen and improve the construction of experimental technical team. We hope that through the continuous improvement of the construction and management of medical laboratory, we can better promote the cultivation of professional talents and the development of disciplines, provide employers with more innovative, application-oriented and high-quality medical professionals, and contribute to the construction of a healthy China strategy.

\section{Funding}

The present study was supported by Hubei University Laboratory Work Research Association (Key Projects in 2019).

\section{Conflicts of Interest}

The authors declare no conflicts of interest regarding the publication of this paper.

\section{References}

Diao, S. J. (2015). Practice and Exploration of Laboratory Construction and Management in Colleges and Universities. Experimental Technology and Management, 32, 233-235.

Dong, L. P., \& Ao, T. Q. (2019). New Ideas and Practice of College Teaching Laboratory Construction under the Background of "Double First-Class". Experimental Technology and Management, 36, 26-28.

Gu, M. M., Xu, W. R., \& Guo, X. K. (2018). Review of the Reform and Development of Basic Medical Experimental Teaching Center for Ten Years. China Higher Medical Education, 4, 4-6.

Ji, R. (2014). Research and Practice of University Experimental Teaching Management Informatization. University Laboratory Work Research, 4, 86-87.

Tang, Y. L., Wang, C. F., \& Guo, Z. W. (2020). Exploration on the Construction and Management of Medical Laboratory under the "9A" Talent Training Mode. Medical Theory and Practice, 33, 1020-1021.

Yang, R., \& Wu, C. W. (2018). Research and Exploration of University Laboratory Construction under the Background of "Mass Entrepreneurship and Innovation". Theoretical Research, 5, 5-6.

Zheng, Z. Y., Li, C. T., Huang, H. C., Dong, A. G., Zhang, Z. L., Ren, J., \& Wang, J. (2019). Investigation and Reflection on the Status Quo of Experimental Technical Teams in Colleges and Universities. Experimental Technology and Management, 36, 244-246+ 275.

Zhu, R. (2018). University Laboratory Construction and Management in the Context of High-Level University Construction. Laboratory Research and Exploration, 37, 278-282. 